\title{
The Application of Inflow Control Device for an Improved Oil Recovery using ECLIPSE
}

\author{
Ambrose A. Ugwu Britt M.E Moldestad \\ Department of Process, Energy and Environmental Technology, University College of Southeast Norway, \\ britt.moldestadeusn. no
}

\begin{abstract}
The rate of inflow to a horizontal well could vary along the completion length due frictional pressure losses or heterogeneity in the reservoir. These variations reduce oil sweep efficiency and the ultimate recovery. Owing to this, it is necessary to manage fluid flow through the reservoir in order to maximize oil recovery along horizontal wells. One increasingly popular approach is to use inflow control devices (ICD) that delay water and gas breakthrough into the well. Inflow control devices balance the inflow coming from the reservoir towards the wellbore by introducing an extra pressure drop. This paper presents the mathematical models used for the implementation of ICD in ECLIPSE. A case using heterogeneous reservoir similar to Troll offshore Norway was illustrated. The simulation result shows that ICD could delay water breakthrough for 262days and water cut after 3000days reduced by $11 \%$. Gas breakgthrough was also reduced by approximately $51 \%$ with ICD.
\end{abstract}

Keywords: ECLIPSE, IOR, ICD, inflow

\section{Introduction}

The challenges introduced by reservoir heterogeneity with horizontal wells tend to increase with increasing well length (Birchenko et al, 2011). Completions with long intervals often have significantly uneven specific inflow distribution along their length. These inflow variations cause premature water or gas breakthrough and should be minimized (Hallundbæk and Hazel, 2016). Advanced well completions have been demonstrated as solution to these challenges. Inflow Control Devices (ICDs) is an established type of advanced completions that provide passive inflow control (Henriksen et al, 2006). ICDs are widely used and can be considered to be a mature well completion technology. One of the challenges is the variation in rock properties. Figure 1 illustrates a typical orifice ICD.

Fluid specific inflow rate tends to increase with increasing well length (Krinis et al, 2009). The

performance of ICDs can be analyzed in detail with the help of various reservoir simulation tools such as ECLIPSE (Birchenko et al, 2011). ECLIPSE includes basic functionality for ICD modeling (Birchenko et al, 2011) and also offers a practical means to capture the effect of annular flow. ICDs are static and usually installed at the beginning of the production life. An alternative technology is the use of autonomous inflow control device with the ability of closing off the flow interval in an event of water or gas breakthrough (Birchenko et al, 2011).

This paper presents ECLIPSE model for the application of ICD in heterogeneous reservoirs. From the mathematical models, the parameters that substantially reduce the inflow variation can be determined. A case study was simulated to illustrate the impact of a specific ICD completion on Inflow performance at Troll offshore Norway.

\section{ECLIPSE Computational Model}

In ECLIPSE, ICD is used to control the inflow profile along a horizontal well or branch by imposing an additional pressure drop between the sand face and the tubing. The device is placed around a section of the tubing and diverts the fluid inflowing from the adjacent part of the formation through a sand screen and then into a spiral before it enters the tubing (Mathiesen et al, 2011).

\subsection{Pressure drop}

The pressure drop across the device is calculated from calibration data, adjusted to allow for the varying density and viscosity of the reservoir fluid flowing

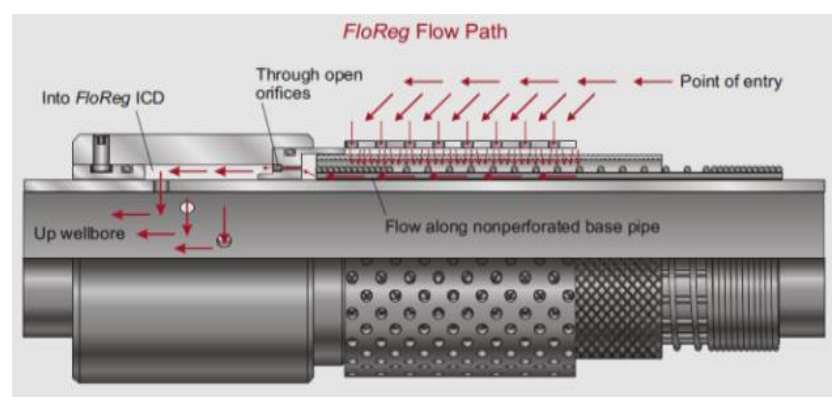

Figure 1. Oriface ICD (Birchenko et al, 2011). 
through the device. The pressure drop equation is shown in (1) below (Schlumberger, 2013).

$$
\left.\partial \mathrm{P}=\left(\frac{\rho_{\text {cal }}}{\rho_{\text {mix }}} \cdot \frac{\mu_{\text {mix }}}{\mu_{\text {cal }}}\right)^{1 / 4} \cdot \frac{\rho_{\text {mix }}}{\rho_{\text {cal }}} \cdot \mathrm{K} \cdot \mathrm{q}^{2}\right)
$$

Here $\rho$ mix is the density of the fluid mixture in the segment at local conditions and $\rho c a l$ is the density of the fluid used to calibrate the ICD. $\mu$ mix is the viscosity of the fluid mixture in the segment at local conditions and $\mu$ mix is the viscosity of the fluid used to calibrate the ICD. $\mathrm{K}$ is the base strength of the ICD defined in (2).

$$
\mathrm{K}=\frac{a_{\text {SICD }}}{\rho_{\text {cal }}}
$$

where aSICD is defined as the strength of the ICD, $q$ is the volume flow rate of fluid mixture through the ICD at local conditions, which is equal to the volume flow rate through the ICD segment multiplied by a scaling factor that depends on the length of the device.

The density of the fluid mixture at local segment conditions is given in (3).

$$
\rho_{\text {mix }}=\alpha_{o} \rho_{o}+\alpha_{w} \rho_{w}+\alpha_{g} \rho_{g}
$$

where $\alpha o, w, g$ is the volume fraction of the free oil, water, gas phases at local conditions and $\rho 0, \mathrm{w}, \mathrm{g}$ is the density of the oil, water, gas phases at local conditions (Schlumberger, 2013).

The viscosity of the fluid mixture at local segment conditions is given in (4)

$$
\mu_{\text {mix }}=\left(\alpha_{\mathrm{o}}+\alpha_{\mathrm{w}}\right) \cdot \mu_{\text {emul }}+\alpha_{\mathrm{g}} \cdot \mu_{\mathrm{g}}
$$

where $\mu$ emul is the viscosity of the oil-water emulsion at local conditions and $\mu \mathrm{g}$ is the gas viscosity at local conditions. The calculation of $\mu \mathrm{emul}$ is described in "Emulsion viscosity" section (Schlumberger, 2013).

To include a series of these devices in a multisegment well, the devices should be represented by segments branching off the tubing as shown in Figure 2. The grid block connections are located in the ICD segments instead of the segments representing the well tubing. The ICD segments should be given a very small length (of the order, say, of the wellbore radius). This length is not used in the pressure loss calculations, but it influences the location of the connections of the grid block in the reservoir. The ICD segments were given the same depth as their 'parent' tubing segments, so that there will be no hydrostatic head across them (Johnson and Oddie, 2004). The pressure loss across an ICD segment is reported as the friction pressure loss; the acceleration pressure loss is set to zero.

\subsection{Emulsion Viscosity}

The emulsion viscosity is a function of the local phase volume fractions in the segment and has differing functional forms at low water in liquid fractions (when oil is the continuous phase) and high water in liquid fractions (when water is the continuous phase) (Schlumberger, 2013). A critical water in liquid fraction as shown in figure 3 is used to select between (5) and (6).

$$
\begin{aligned}
& \mu_{\text {wio }}=\mu_{\mathrm{o}} \cdot\left(\frac{1}{1-\left(\frac{0.8415}{0.7480} \cdot \alpha_{\mathrm{wl}}\right)}\right)^{2.5} \\
& \mu_{\text {oiw }}=\mu_{\mathrm{w}} \cdot\left(\frac{1}{1-\left(\frac{0.6019}{0.6410} \cdot \alpha_{\mathrm{ol}}\right)}\right)^{2.5}
\end{aligned}
$$

where $\mu_{-}$wio is the water-in-oil emulsion viscosity (when oil is the continuous phase), $\mu_{-}$oiw is the oil-inwater emulsion viscosity (when water is the continuous phase) and $\mu_{-} \mathrm{o}$ is the oil viscosity at local conditions. $\mu_{-} \mathrm{w}$ is the water viscosity at local conditions, $\alpha_{-} w \mathrm{wl}$ the local water in liquid fraction and $\alpha \_$ol is the local oil in liquid fraction.

The water-in-oil viscosity is subject to an upper limit expressed as a maximum ratio of water-in-oil viscosity to oil viscosity. This usually results in a 'plateau' region within which the water-in-oil viscosity is at its maximum permitted value as shown schematically in Figure 3, with the maximum viscosity ratio set at 5.0 (Schlumberger, 2013).

This upper limit also applies to the oil-in-water viscosity, but is less commonly encountered. At the critical water in liquid fraction there is a jump in emulsion viscosity as the continuous phase changes. Such a discontinuity would cause stability problems in the simulator and a transition region is defined about the critical water in liquid fraction to avoid this. In this region the emulsion viscosity is linearly interpolated between the water-in-oil and oil-in-water viscosities at the edges of the region; the viscosity is thus a continuous function of the water in liquid fraction. This transition region is presented schematically in Figure 3, with the linear interpolation shown in red between points B and C (Schlumberger, 2013).

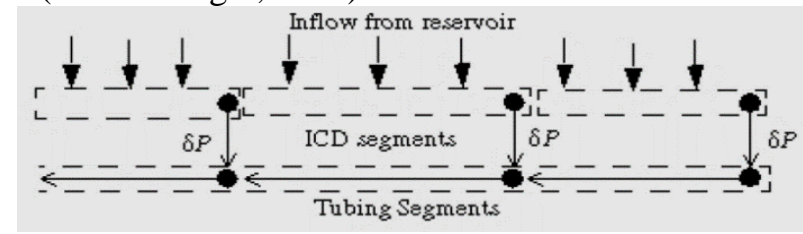

Figure 2. Segments ICDs along the well (Schlumberger, 2013). 


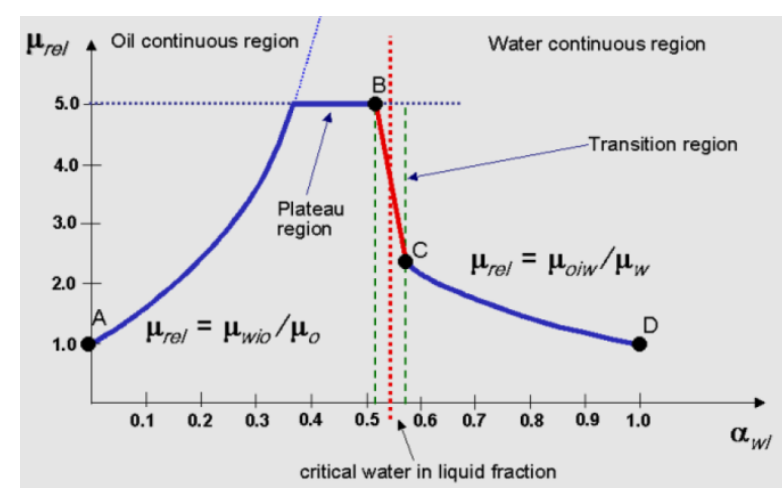

Figure 3. Phase Ttransition region about the critical water in liquid fraction (Schlumberger, 2013).

between the water-in-oil and oil-in-water viscosities at the edges of the region; the viscosity is thus a continuous function of the water in liquid fraction. This transition region is presented schematically in Figure 3, with the linear interpolation shown in red between points $B$ and C (Schlumberger, 2013).

\section{Case Study}

A study was considered with reservoir conditions similar to the Troll field, Norway to illustrate the effect of ICD on oil recovery, reservoir sweep, delay in water breakthrough and decrease in water cut. Troll is a large subsea offshore Norway. The challenge is to drill and complete well in a way that gas and water do not have easy access to the production well (Henriksen et al., 2006). The main oil reservoir at Troll is the Late Jurassic Sognefjord Formation. This formation consists of Sandstone and siltstone with thickness of about $160 \mathrm{~m}$. The porosity vary between $30-35 \%$ and permeability between $1-20 \mathrm{D}$. The reservoir driving mechanism is mainly gas expansion and water drive. Horizontal wells are located close to the oil-water contact in order to reduce gas breakthrough (Henriksen et al., 2006).

Simulation was carried out for 3000 days. Water drive was achieved by connecting analytical aquifer (Fetkovich aquifer) at the bottom of the reservoir. Frictional pressure drop and variation in permeability will lead to non-uniform inflow profile along the production well (Aakre et al., 2013). ICDs are set at two segments along the production open hole section to distribute downhole pressure to optimize fluid inflow along the entire production interval. Water saturation profile shown in Figure 4 indicates that more water is produced at the $225 \mathrm{~m}$ and $375 \mathrm{~m}$ positions of the production well due to high permeability at these positions. To reduce water breakthrough, ICDs were placed at these positions. Each ICD joint is about $12 \mathrm{~m}$ in length and about $3 \mathrm{~mm}$ nozzle diameter. A base case without water ICD was considered for reference.

\subsection{Geometry}

Rectangular reservoir geometry was considered with the dimension 500m x 450m x 70m. The multi-segment horizontal production (PROD) well is of length $450 \mathrm{~m}$. The reservoir is heterogeneous with varying permeability from 1 to 20 Darcy. The areas of high permeability represents defeat in the reservoir as shown in figures 5 and 6.

\subsection{Reservoir Conditions}

The reservoir is heterogeneous and consists of waterwetted rock. Although the reservoir fluid consists of live black oil, gas production was not considered for simplicity. The composition of oil components is assumed to be constant relative to pressure and time. It is also assumed that the reservoir fluid is Newtonian and that Darcy's law applies. The reservoir conditions used for the simulation are summarized in Table 2.

\subsection{Assumptions}

The following assumptions were made regarding the inflow:

1. Darcy's law applies to the flow through the reservoir.

2. The flow into the well is at steady or pseudosteady state.

3. The flow into the well is at steady or pseudosteady state.

4. The distance between the well and the reservoir boundary is longer than the length of the well length.

The following assumptions were made about the ICDs:

1. There is no flow in the annulus parallel to the base pipe. This means that fluid flows from reservoir directly through ICD screens into the base pipe (Ouyang, 2009).

2. ICDs installed are of the same strength. This is the most common type of ICD application due to the relative simplicity of its design and installation operation (Henriksen et al, 2006). This is done in order to reduce the operational risks (Birchenko et al, 2010; Muradov et al, 2010).

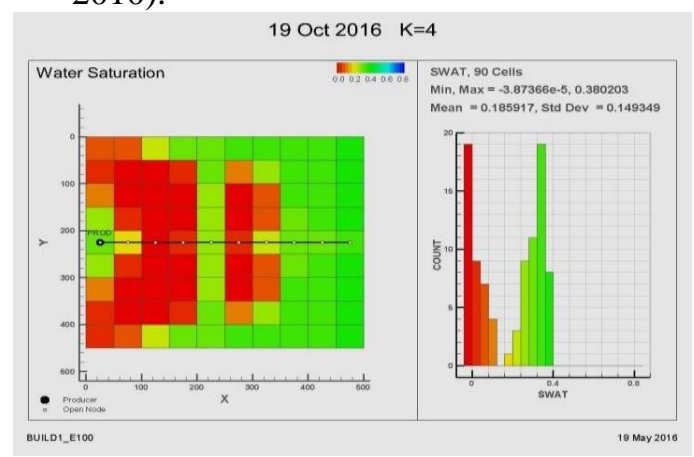

Figure 4. ICD positions along the well. 


\subsection{Initial Conditions}

Initially, the reservoir is assumed to be in hydrostatic equilibrium consisting of only oil. The initial pressure is greater than the bubble point and water has much higher mobililty than oil. Table 1 shows the initial conditions considered during the simulation.

\section{Result and Discussion}

In this simulation, the effect of ICD completion on oil, water and gas production was investigated. Also the reservoir pressure trend recovery was discussed. A base case without ICD completion was considered as reference.

Table 1. Initial Conditions.

\begin{tabular}{|l|l|l|}
\hline Initial condition & Value & Unit \\
\hline Reservoir pressure & 320 & Bar \\
\hline Bottomhole pressure & 310 & Bar \\
\hline Bubble point pressure & 182 & Bar \\
\hline Oil saturation & 1 & - \\
\hline Water saturation & 0 & - \\
\hline Gas saturation & 0 & - \\
\hline
\end{tabular}

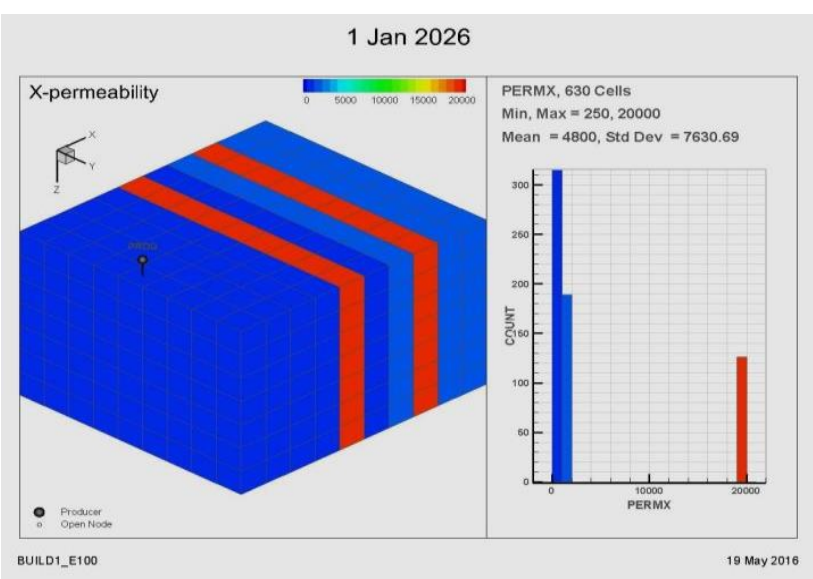

Figure 5. Reservoir geometry showing the distribution of $\mathrm{X}$ and $\mathrm{Y}$ permeability.

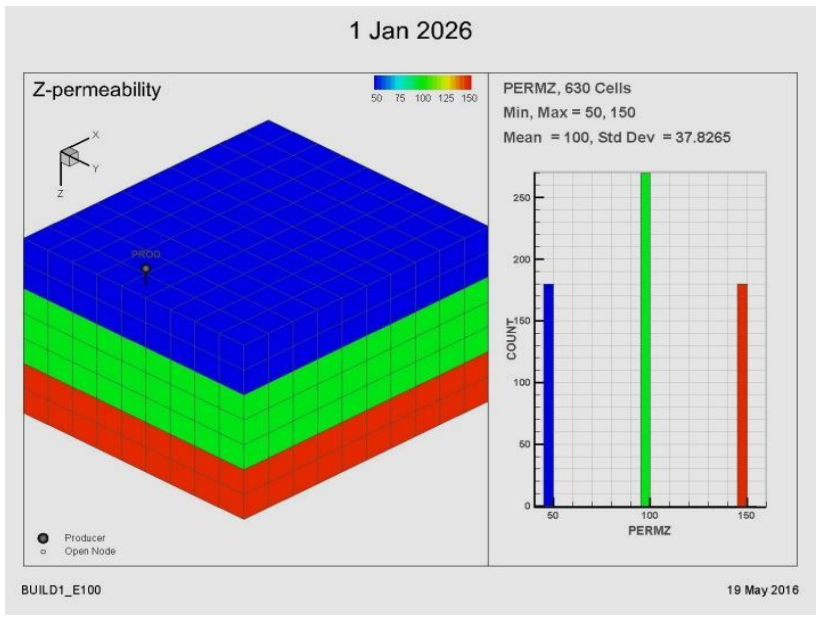

Figure 6. Reservoir geometry showing the distribution of Z- permeability.

\subsection{Reservoir Pressure}

Figure 7 shows the simulated reservoir pressure trend. The ratio of the total pressure drop without ICD completion to the total pressure drop with ICD is about 52. The high pressure drop for the case without ICD may be due to more reservoir depletion as a result of high water production. ICD tends to maintain the reservoir pressure by retaining water in the reservoir pore spaces.

\subsection{Water Production}

The water cut trend is shown in Figure 8. It is observed that water breakthrough is delayed for 262 days (about 66\%) with the installation of ICD. Also the water cut is

Table 2. Reservoir Conditions.

\begin{tabular}{|l|l|l|}
\hline Parameter & Value & Unit \\
\hline Components & Oil, water, gas & - \\
\hline Wettability & Water-wetted & - \\
\hline Porosity & 0.30 & - \\
\hline X Permeability & $0.1-20$ & Darcy \\
\hline Y Permeability & $0.1-20$ & Darcy \\
\hline Z Permeability & $0.1-1$ & Darcy \\
\hline Rock compressibility & $5.0 \mathrm{E}-5 @ 10 \mathrm{Bar}$ & $/$ /Bar \\
\hline Oil gravity & 35 & ${ }^{\circ} \mathrm{Api}$ \\
\hline Residual oil sat & 0.3 & - \\
\hline Oil viscosity & $10 @$ 320Bar & $\mathrm{cP}$ \\
\hline Water Density & 1000 & $\mathrm{~kg} / \mathrm{m}^{3}$ \\
\hline Water viscosity & 0.5 & $\mathrm{cP}$ \\
\hline Connate water sat & 0.2 & - \\
\hline Gas density & 1 & $\mathrm{~kg} / \mathrm{m}^{3}$ \\
\hline Well length & 450 & $\mathrm{~m}$ \\
\hline Target well flow rate & 2000 & $\mathrm{Sm}^{3} / \mathrm{day}^{3}$ \\
\hline ICD Length & 12 & $\mathrm{~m}$ \\
\hline ICD Strength & 0.00021 & $\begin{array}{l}\mathrm{bar} /\left(\mathrm{Rm}^{3} /\right. \\
\text { day })^{2}\end{array}$ \\
\hline ICD nozzle diameter & 3 & $\mathrm{~mm}$ \\
\hline Simulation time & 3000 & $\mathrm{days}$ \\
\hline No of Grids & $630(10 \times 9 \times 7)$ & - \\
\hline
\end{tabular}

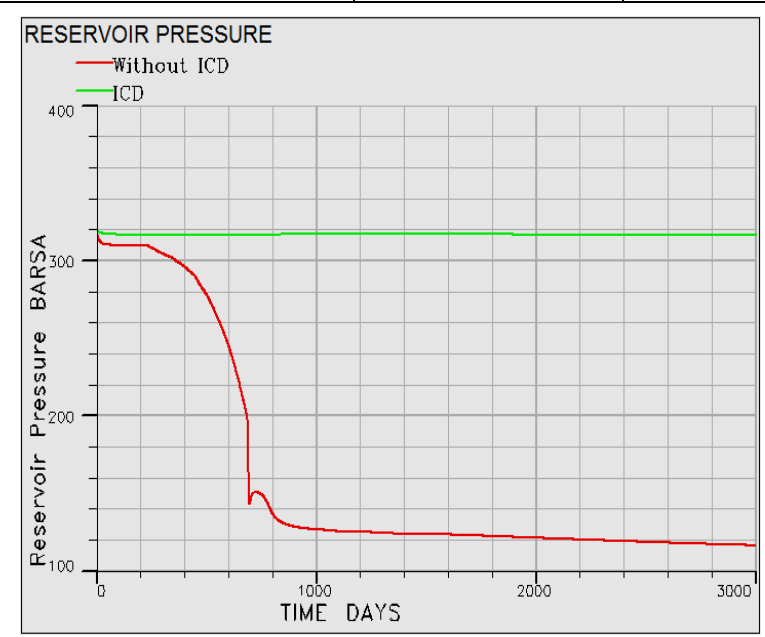

Figure 7. Reservoir Pressure Trend. 
reduced with about $11 \%$ after 3000 days with the ICD completion. This would be attributed to the restriction imposed on water flow due to the additional pressure drop with the ICD.

\subsection{Oil Production}

Figure 9 shows the oil production rate with and without ICD respectively. Although the water breakthrough is delayed with ICD, the oil production rate is lower compared with the case without ICD. After water breakthrough, the production rate drops more rapidly for the case without ICD. This may be attributed to rapid water production as there is no restriction towards water production. Shock wave was propagated at about 690th day due to sudden opening of valve to match up the production target for the case without ICD. This shock wave can lead to very high pressure buildup which could make the system to fail. With the ICD, this phenomenon is annulled through its equalization effect on flow variation making the system stable throughout the production life.

Although well productivity is reduced by approximately $42 \%$, there is an improved degree of inflow equalization through ICD completion. The accumulated oil production is shown in Figure 10. From the slope, production would be sustained more and the accumulated oil production expected to be higher over a long time with ICD completion.

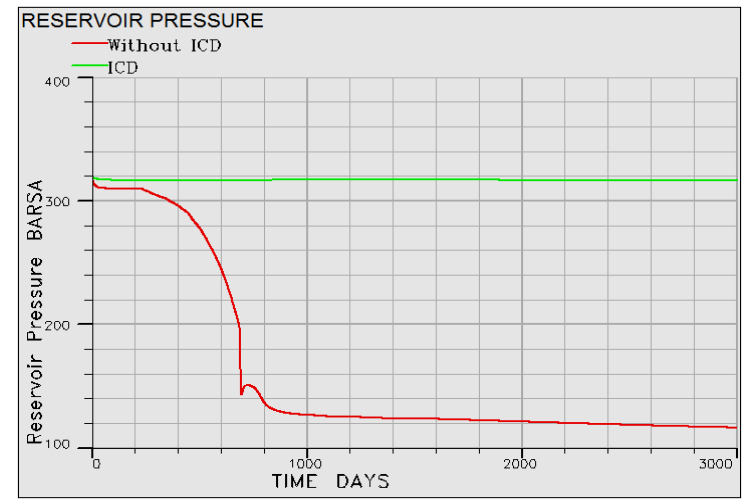

Figure 8. Reservoir Pressure Trend.

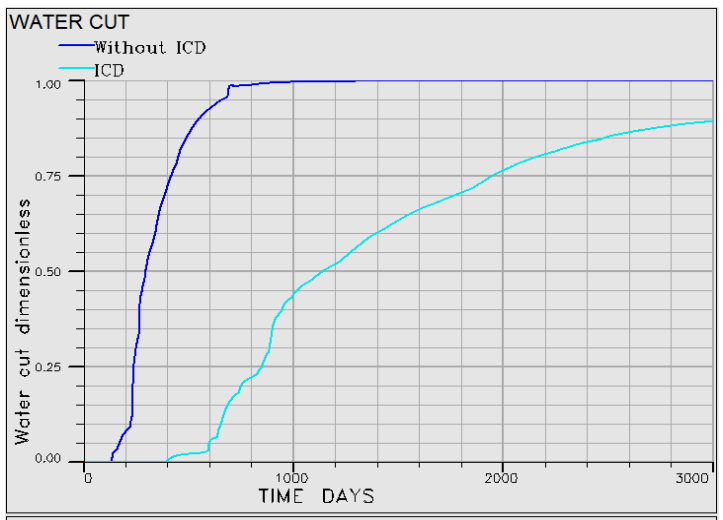

Figure 9. Trend of water cut.

\subsection{Gas Production}

Figure 11 shows the gas production rate with ICD and without ICD completions respectively. It can be seen that gas production rate is less with ICD completion throughout the production life. This may be attributed to rapid water production in the case without ICD as there is no restriction towards water production. Shock wave was propagated at about 690th day due to sudden opening of valve to match up production target for the case without ICD. This shock wave can lead to system failure as result of high pressure. This shock effect is not observed with ICD completion due to the restriction imposed by additional pressure drop and the equalization effect on flow variation. With ICD completion, the system is stable throughout the production life. There is about $51 \%$ decrease in gas production as depicted in Figure 12 with ICD completion. This increase in gas production for the case without ICD may reduce well performance and recovery significantly as oppose to ICD completion.

\section{Conclusions}

This paper presents the mathematical models used for the implementation of ICD in ECLIPSE reservoir simulator. A case study using similar reservoir conditions as Troll offshore Norway was simulated to illustrate the effect of ICD in a heterogeneous reservoir. Analysis of oil, water and gas production was made within a simulation period of 3000 days.

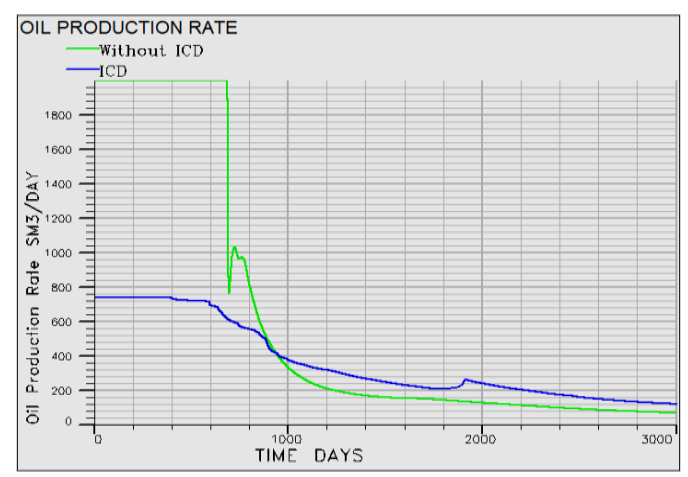

Figure 10. Trend of Oil Production Rate.

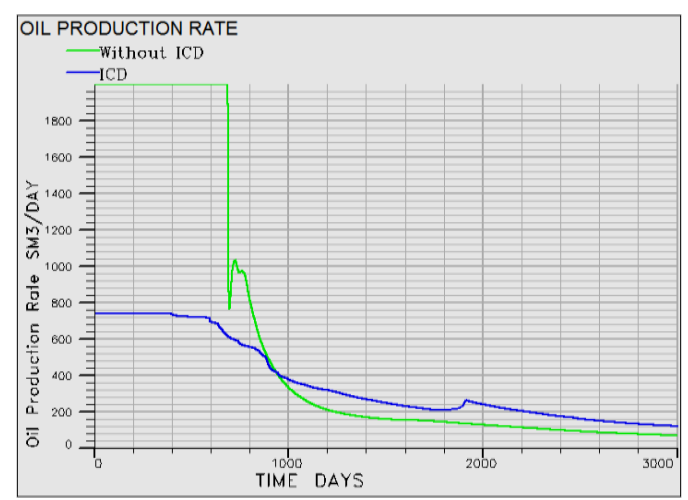

Figure 11. Trend of Oil Production Rate. 


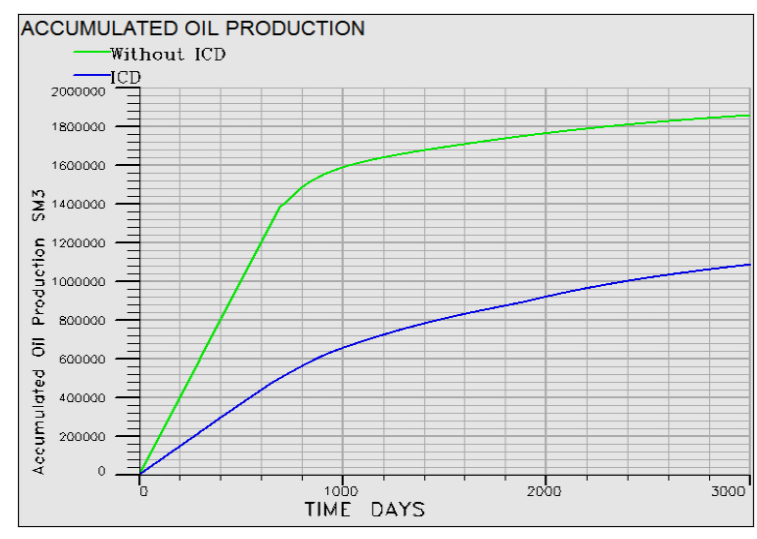

Figure 12. Trend of Accumulated Oil Production.

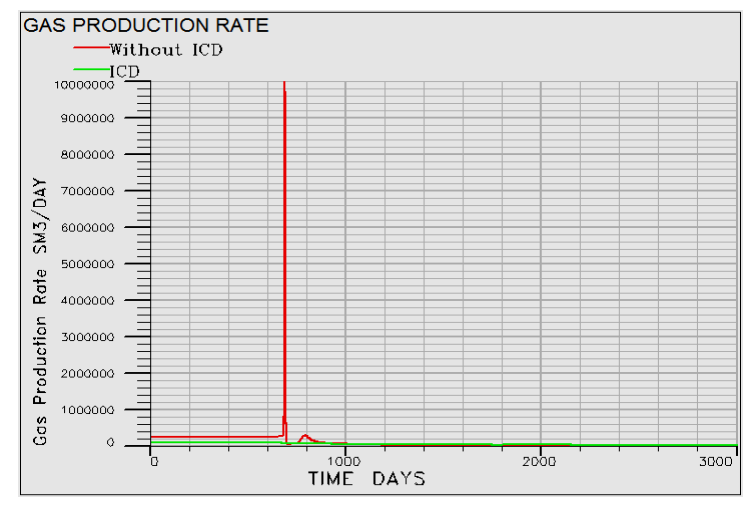

Figure 13. Trend of Gas Production Rate.

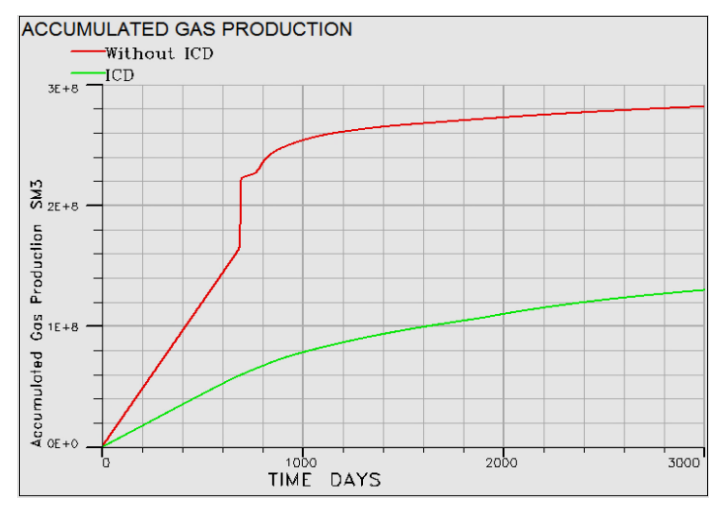

Figure 14. Trend of the accumulated gas production.

Result shows that with ICD completion, water breakthrough was delayed with 262 day and water cut after 3000 days was reduced by $11 \%$. Despite the delay in water breakthrough, the oil production rate was reduced due to flow restriction by additional pressure drop with ICD completion. A trade-off between well productivity and inflow equalization is important. Although well productivity is reduced by approximately $42 \%$, there is an improved degree of inflow equalization through ICD completion. Gas production was decreased by approximately $51 \%$ with ICD completion. With this reduction in gas production, well performance and ultimate recovery would improve. Result also indicates that the case with ICD completion sustains the reservoir pressure as water is forced to occupy the pore spaces of the reservoir.

It would be inferred that although ICD delays water and gas breakthrough, it could not stop the breakthrough. It would be appropriate to apply autonomous inflow control device instead, to stop gas and water breakthrough.

\section{Acknowledgements}

We would like to thank the management of University College of Southeast Norway and Inflow Control AS for providing the facility required for this study.

\section{References}

H. Aakre, B. Halvorsen, B. Werswick and V. Mathiesen. Smart well with autonomous inflow control valve technology. In Proceedings of the SPE Middle East Oil and Gas Show and Conference, 2013.

V. Birchenko, A. I. Bejan, A. Usnich and D. Davies. Application of inflow control devices to heterogeneous reservoirs. Journal of Petroleum Science and Engineering, 78(2): 534-541, 2011.

V. Birchenko, K. Muradov and D. Davies. Modeling of the Heel-toe Effect in a Horizontal Well with Inflow Control Devices. In Proceedings of the ECMOR XII-12th European Conference on the Mathematics of Oil Recovery, 2010.

V. Birchenko, K. Muradov and D. Davies. Reduction of the horizontal well's heel-toe effect with inflow control devices. Journal of Petroleum Science and Engineering, 75(1): 244-250, 2010.

J. Hallundbæk and P. Hazel. Inflow control in a production casing. Google Patents, 2016.

K. H. Henriksen, E. I. Gule and J. R. Augustine. Case study: the application of inflow control devices in the troll field. In Proceedings of the SPE Europec/EAGE Annual Conference and Exhibition, 2006.

C. D. Johnson and G. M. Oddie. Flow control regulation method and apparatus. Google Patents, 2004.

D. Krinis, D. E. Hembling, N. J. Al-Dawood, S. A. Al-Qatari, S. Simonian and G. Salerno. Optimizing Horizontal Well Performance In Non-Uniform Pressure Environments Using Passive Inflow Control Devices. In Proceedings of the Offshore Technology Conference, 2009.

V. Mathiesen, B. Werswick, H. Aakre and G. Elseth, G. Autonomous Valve- A Game Changer of Inflow Control in Horizontal Wells. In Proceedings of the Offshore Europe, 2011.

K. Muradov, V, Birchenko and D. Davies. Modeling of the Heel-toe Effect in a Horizontal Well with Inflow Control Devices. In Proceedings of the 12th European Conference on the Mathematics of Oil Recovery, 2010.

L. B. Ouyang. Practical consideration of an inflow-control device application for reducing water production. In Proceedings of the SPE Annual Technical Conference and Exhibition, 2009.

Schlumberger Limited. ECLIPSE Reservoir Simulation Software - Technical Description, 2013. 